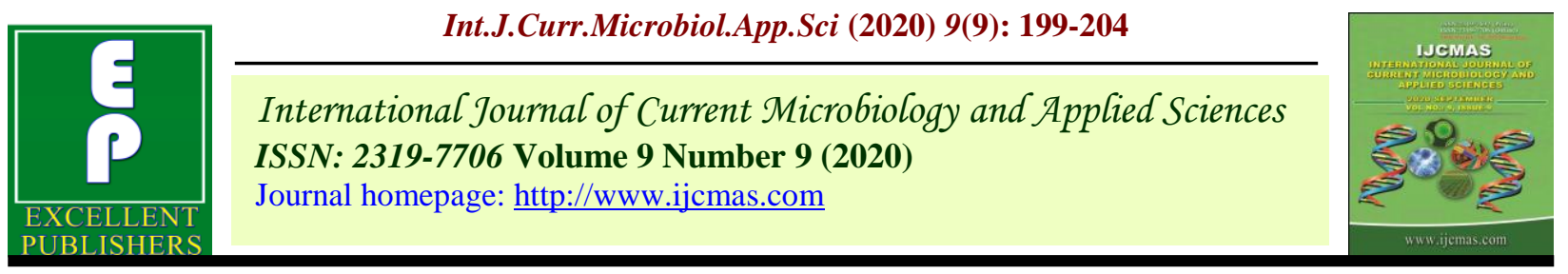

Original Research Article

https://doi.org/10.20546/ijcmas.2020.909.025

\title{
Knowledge of the Rural Women Regarding Selected Government Schemes
}

\author{
Rishika Negi*, Dhriti Solanki and Rajshree Upadhyay \\ Department of Extension Education and Communication Management, \\ College of Community and Applied Sciences, Maharana Pratap University of Agriculture and \\ Technology, Udaipur, India \\ *Corresponding author
}

\section{A B S T R A C T}

\begin{tabular}{|l|}
\hline Ke y w o r d s \\
Government \\
schemes, \\
Knowledge, \\
Rural women
\end{tabular}

\section{Introduction}

India is integrally known as a land of villages and eventually our growth will be based on the advancement of village people. According to census 2011 out of 1210 million Indian population, about 833.1 million population lives in rural areas which is totally dependent on agriculture either directly or indirectly. So, it is very important to develop villages for development of the country (https://en.wikipedia.org/wiki/2011_Census_o f_India).

In rural areas women play role as the productive and reproductive part of the community and are not aware of their needs, rights and those empowering processes which helps to achieve economic and social betterment in life so that they can become a self-reliant woman. Therefore, government of India has launched several schemes and programmes to raise the socio-economic status of women for the overall development of the family, village and nation. Schemes of government which are presently in focus are:

\section{Pradhan Mantri Sukanya Samriddhi Yojana (SSY)}

2. Pradhan Mantri Micro Units Development and Refinance Agency (MUDRA) 
3. Pradhan Mantri Jeevan Jyoti Bima Yojana (JJBY)

4. Pradhan Mantri Suraksha Bima Yojana (SBY)

5. Pradhan Mantri Deen Dayal Upadhyay Gram Jyoti Yojana (DDUGJY)

6.Pradhan Mantri Ujjawala Yojana (UY)

7.Pradhan Mantri Krishi Sinchaai Yojana (KSY)

8. Pradhan Mantri Soil Health Card Scheme (SHCS)

The present investigation has been planned with an objective to study the knowledge of rural women about selected government schemes.

\section{Materials and Methods}

The study was conducted in four villages viz. Danda, Lelta, Simog, Dimou of randomly selected block Kalsi of Dehradun district (Uttarakhand). From each village, 25 women were selected randomly, thereby making a total sample of 100 respondents. Data were collected with the help of personal interview schedule which consisted of different aspects of the schemes i.e. name, objectives, beneficiaries and provisions under the scheme. Frequency, percentage, Mean Per cent Score and Mean Weighted Score were used for analyzing the data statistically.

\section{Measurement of knowledge}

The knowledge test of the selected government schemes comprised of general knowledge regarding selected government schemes and then specific knowledge separately for each scheme i.e. knowledge regarding PM SSY, PM MUDRA Yojana,
PM JJBY, PM SBY, PM DDUGJY, PM UY, PMKSY and PM SHCS. For scoring, each correct answer was assigned one score. The details of the number of questions with scores about the general knowledge and specific knowledge regarding the selected schemes are given in Table 1.

Since the maximum score for each scheme varied therefore the respondent's scores were converted into MPS and then based on equidistance categories, respondents were categorized into three groups as shown in Table 1.

\section{Results and Discussion}

Background information of the
respondents

Age: Data in Table 2 reveal that majority of the respondents $(66 \%)$ belonged to the age group of 18- 30 years, while less than one third of the respondents were in the age group of $31-45$ years (28\%). Only 6 per cent of the respondents were in 46- 60 years of age group.

Education: Educational profile of the respondents presented in Table 2 indicates that 32 per cent of the respondents were illiterate, whereas 27 per cent of the respondents could read and write. Similarly 21 per cent of the respondents were educated up to primary level, 16 per cent of the respondents were educated up to middle school and few (4\%) of the respondents were educated up to high school. Therefore it can be concluded from the findings that maximum (41\%) were educated up to primary school and above.

Occupation: It is clear from Table 2 that majority of the respondents (77\%) had farming as their main occupation and 21per cent of the respondents had service/ business 
as their occupation and only 4 per cent of the respondents were farm labor.

Organizational membership: As far as organizational membership is concerned, it is evident from Table 2 that 42 per cent of the respondents were the members of non-formal organization, 17 per cent were the member of formal organization and 41 per cent were not the members of any organization.

Land holding: Table 2 shows that majority of the respondents $(62 \%)$ did not possess any land and 38 had land up to 1- 2.5 acres.

Media ownership: Data in the Table 2 reveal that high majority of the respondents $(88 \%)$ had radio whereas only $(12 \%)$ of the respondents owned television.

Socio- economic status: Based on the social and economic variables, socio-economic status was calculated and analyzed as high, medium and low and presented in Table 3, which shows that majority of the respondents (79\%) belonged to low socio- economic status and 21petr cent belonged to the category of medium socio-economic status. None of the respondents belonged to high socio-economic status.

Knowledge of the respondents about the selected government schemes

To find out knowledge of the respondents about selected government schemes mean per cent score was calculated and on the basis of MPS the respondents were categorized into three knowledge categories viz. good, average and poor. The results are presented in table 4 .

Table 4 clearly reveals that the respondents possessed poor knowledge about SSY as their MPS was found to be 32.76. Categorization of the respondents in to various knowledge categories highlight that only 8 per cent of the respondents possessed good knowledge about SSY, 48 per cent respondents possessed average knowledge and 44 per cent of the respondents possessed poor knowledge. Similarly in MUDRA yojana (8\%) of the respondents have good knowledge, $(50 \%)$ of the respondents have average knowledge whereas $(42 \%)$ of the respondents have poor knowledge with the mean per cent score of 26.61 as depicted in Table 4 and Fig. 1. With regard to JJB Yojana majority of the respondents (84\%) were under poor category with the mean per cent score of 10.37 as depicted in Table 4. and Fig. 1. Only 11 per cent of the respondents had good knowledge about the scheme. Similarly in case of Suraksha Bima Yojana majority of the respondents had poor knowledge with mean per cent score 13.09.

Another scheme under the study was DDUGJY in which only 19 per cent of the respondents had good knowledge about the scheme, while 70 per cent of the respondents belonged to poor knowledge category. With regard to PM Ujjawala Yojana majority of the respondents $(66 \%)$ belonged to average knowledge category with mean per cent score 39.55 as depicted in Table 4 and Fig. 1.

Table.1 Knowledge categories with score range

\begin{tabular}{|c|c|c|}
\hline S.No. & Categories & MPS \\
\hline $\mathbf{1}$ & Good & $66.67-100$ \\
\hline $\mathbf{2}$ & Average & $33.34-66.66$ \\
\hline $\mathbf{3}$ & Poor & $0-33.33$ \\
\hline
\end{tabular}


Table.2 Distribution of the respondents according to their personal variables $n=100$

\begin{tabular}{|c|c|c|}
\hline S.No. & Variables & $\mathbf{f} /(\%)$ \\
\hline 1 & \multicolumn{2}{|l|}{ Age } \\
\hline i. & $18-30$ years & 66 \\
\hline ii. & $31-45$ years & 28 \\
\hline iii. & $46-60$ years & 6 \\
\hline iv. & Above 60 years & 0 \\
\hline 2 & \multicolumn{2}{|l|}{ Education } \\
\hline i. & Illiterate & 32 \\
\hline ii. & Can read and write & 27 \\
\hline iii. & Primary & 21 \\
\hline iv. & Middle & 16 \\
\hline v. & High School & 4 \\
\hline vi. & Sr. Secondary School & 0 \\
\hline vii. & Graduation and above & 0 \\
\hline 3. & \multicolumn{2}{|l|}{ Occupation } \\
\hline i. & Farming & 77 \\
\hline ii. & Business/service & 21 \\
\hline iii. & Artisans/ craftsman & 0 \\
\hline iv. & Farm labor & 2 \\
\hline 4. & \multicolumn{2}{|l|}{ Organizational membership } \\
\hline i. & No membership & 41 \\
\hline ii. & Member of formal organization & 17 \\
\hline iii. & Member of Non formal organization & 42 \\
\hline 5. & \multicolumn{2}{|l|}{ Land holding } \\
\hline i. & No land & 62 \\
\hline ii. & $1.0-2.5$ acres & 38 \\
\hline iii. & $2.6-5.0$ acres & 0 \\
\hline iv. & $5.1-10.0$ acres & 0 \\
\hline 6. & \multicolumn{2}{|l|}{ Housing } \\
\hline i. & Kutcha house & 18 \\
\hline ii. & Mixed house & 57 \\
\hline iii. & Pucca house & 25 \\
\hline 7. & \multicolumn{2}{|l|}{ Livestock ownership } \\
\hline i. & No livestock & 25 \\
\hline ii. & Small herd size & 51 \\
\hline iii. & Medium herd size & 24 \\
\hline 8. & \multicolumn{2}{|l|}{ Dwelling for livestock } \\
\hline i. & No dwelling & 25 \\
\hline ii. & Kutcha & 63 \\
\hline iii. & Pucca & 12 \\
\hline 9. & \multicolumn{2}{|l|}{ Media ownership } \\
\hline i. & Nil & 0 \\
\hline ii. & Newspaper /Magazine & 0 \\
\hline iii. & Radio /Transistor & 88 \\
\hline iv. & Television & 12 \\
\hline
\end{tabular}


Table.3 Distribution of respondents on the basis of their socio- economic status $n=100$

\begin{tabular}{|c|c|c|}
\hline S.No. & Categories & $\mathbf{f} / \mathbf{( \% )}$ \\
\hline $\mathbf{1}$ & Low & 79 \\
\hline $\mathbf{2}$ & Medium & 21 \\
\hline $\mathbf{3}$ & High & 0 \\
\hline
\end{tabular}

Table.4 Knowledge of the respondents about the selected government schemes $n=100$

\begin{tabular}{|l|l|c|c|c|c|}
\hline \multirow{2}{*}{ S.No. } & \multicolumn{1}{|c|}{ Name of the scheme } & \multicolumn{2}{|c|}{ Knowledge categories (f/\%) } & \multirow{2}{*}{ MPS } \\
\cline { 3 - 5 } & & Good & Average & Poor & \\
\hline 1. & PM Sukanya Samriddhi Yojana & 8 & 48 & 44 & 32.76 \\
\hline 2. & PM MUDRA Yojana & 8 & 50 & 42 & 26.61 \\
\hline $\mathbf{3 .}$ & PM Jeevan Jyoti Bima Yojana & 11 & 5 & 84 & 10.37 \\
\hline $\mathbf{4 .}$ & PM Suraksha Bima Yojana & 11 & 22 & 67 & 13.09 \\
\hline $\mathbf{5 .}$ & $\begin{array}{l}\text { PM Deen Dayal Upadhyaya Gram } \\
\text { Jyoti Yojana }\end{array}$ & 19 & 11 & 70 & 18.36 \\
\hline 6. & PM Ujjawala Yojana & 5 & 66 & 29 & 39.55 \\
\hline 7. & PM Krishi Sinchaayi Yojana & 4 & 19 & 77 & 12.00 \\
\hline 8. & PM Soil Health Card & 21 & 28 & 51 & 24.33 \\
\hline & Overall & $\mathbf{6}$ & $\mathbf{3 1}$ & $\mathbf{6 3}$ & $\mathbf{2 2 . 4 2}$ \\
\hline
\end{tabular}

Fig.1 Overall Knowledge of the respondents about total selected schemes

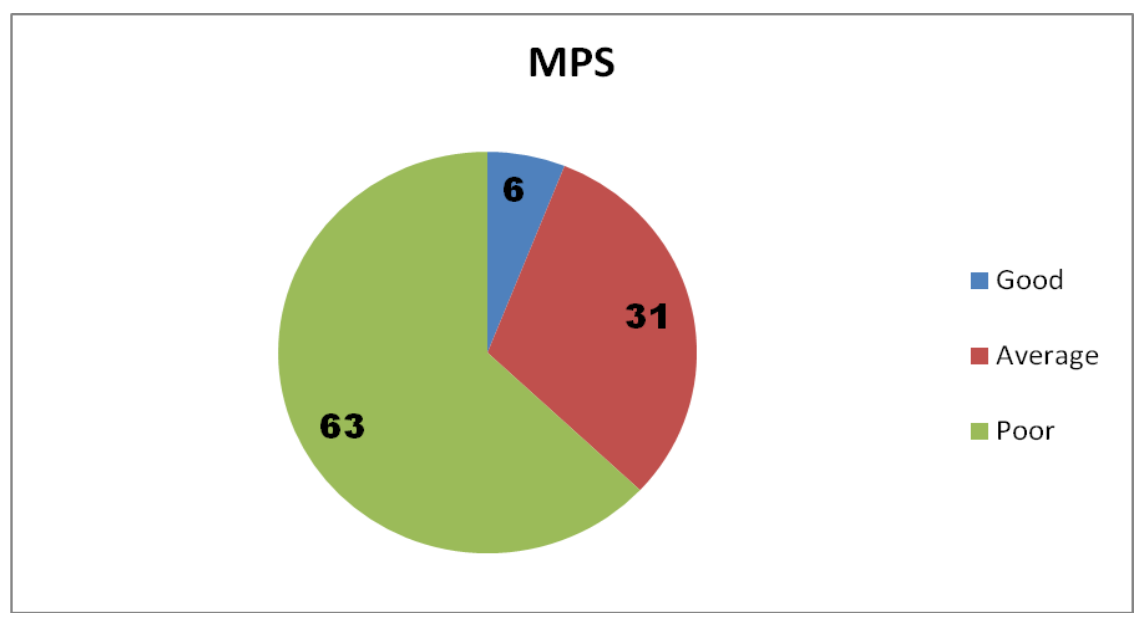

Another scheme PM Krishi Sinchaayi Yojana was related to agriculture. Data in Table 5 clearly states that mean per cent score of KSY was 12.00 with majority $(77 \%)$ of the respondents were belonging to poor knowledge category. The respondents under the category of good knowledge were only 4 per cent.
The overall knowledge about Soil Health Card scheme (MPS 24.33) reveals that 51 per cent of the respondents belonged to poor knowledge category followed by 28 per cent respondents with average knowledge and 21 per cent of the respondents were under good knowledge category. 
The overall knowledge of the respondents with regard to selected government schemes as given in Table 5 and Figure 2 depicts that majority of the respondents possessed poor knowledge about the government schemes with overall mean per cent score of 22.42.Distribution of the respondents into various knowledge categories reveals that majority of the respondents $(63 \%)$ belonged to poor knowledge category followed by 31 per cent under average knowledge and only 6 per cent respondents belonged to good category of knowledge.

The findings are in line with the study conducted by Bori (2014) on "Impact of Swarnjayanti Gram Swarozgar Yojana (SGSY) on poverty alleviation in Golaghat district, Assam" that 43.75 per cent respondents knew about SGSY scheme and 23.75 per cent of the respondents had high knowledge and 32.50 per cent of them had low level of knowledge about the scheme.

The findings get support by Tatyaso (2016) on "Knowledge and adoption of beneficiary farmers of crop insurance scheme in Solapur District" who reported that more than two third (70.84 \%) of the respondents had complete knowledge about insurance schemes for agriculture, while $(20.83 \%)$ of the respondents had no knowledge and only $(8.33 \%)$ had partial knowledge about this aspect.

The findings of the study get support from the study conducted by Diwan (2017) on "National Rural Livelihood Mission" revealed that 65 per cent respondents knew about its objective and 38 per cent knew about the starting year of the programme in the village. More than one third of the respondents $(35 \%)$ knew about the name of the programme but only 26 per cent respondents knew complete name of the programme. With respect to overall knowledge of respondents, more than half of the respondents $(52 \%)$ had average knowledge about the programme, whereas 48 per cent respondents had good knowledge about NRLM.

Based on the findings it can be concluded that the respondents had poor knowledge about all the selected government schemes except PM Ujjawala Yojana in which they possessed average knowledge. The reason for poor knowledge of the respondents might be due to their limited exposure to the outside world and lack of efforts on part of the government officials for popularization of the schemes at grass root level.

\section{References}

Census. 2011.Report cited from https://en.wikipedia.org/wiki/2011_Censu S_of_India. Retrieved on 10/1/2020

Bori, B. 2014. Impact of Swarnjayanti Gram Swarozgar Yojana (SGSY) on poverty alleviation in Golaghat District, Assam. IOSR Journal of Humanities and Social Science. 19(9): 53-56.

Tatyaso, R. N. 2016. Knowledge and adoption of beneficiary farmers of crop insurance scheme in Solapur District. M.Sc. thesis submitted to Mahatma Phule Krishi Vidyapeeth, Rahuri, Maharashtra.

Diwan, P. 2017. Assessment of knowledge and benefits of National Rural Livelihood Mission (NRLM) among rural women of Udaipur District. M.Sc. thesis submitted to Maharana Pratap University of Agriculture and Technology, Udaipur, Rajasthan.

\section{How to cite this article:}

Rishika Negi, Dhriti Solanki and Rajshree Upadhyay. 2020. Knowledge of the Rural Women Regarding Selected Government Schemes. Int.J.Curr.Microbiol.App.Sci. 9(09): 199-204. doi: https://doi.org/10.20546/ijcmas.2020.909.025 